\title{
Designing Container Shipping Routes for Heterogeneous Fleet for Coastal Services
}

\author{
Che Kingsley \\ Shanghai Maritime University, Shanghai, China \\ Email: kingsleyche01@gmail.com
}

How to cite this paper: Kingsley, C. (2019) Designing Container Shipping Routes for Heterogeneous Fleet for Coastal Services. Open Journal of Applied Sciences, 9, 799817.

https://doi.org/10.4236/ojapps.2019.911065

Received: October 31, 2019

Accepted: November 23, 2019

Published: November 26, 2019

Copyright $\odot 2019$ by author(s) and Scientific Research Publishing Inc. This work is licensed under the Creative Commons Attribution International License (CC BY 4.0).

http://creativecommons.org/licenses/by/4.0/

(c) (i) Open Access

\begin{abstract}
Shipping companies operating liner services keep facing a high level of competition because of the increasing demand for these operators to provide fast, efficient, effective and reliable service. It is challenging for these liner operators to offer such services and still be competitive without strategic planning. It, therefore, makes planning and scheduling of shipping routes essential for the smooth operation of liner ships, especially shipping lines operating heterogeneously mixed size fleets. This paper aims to solve a heterogeneously mixed size fleet problem by using an operation research method with the implementation of linear programming to develop optimal shipping routes for a fleet of five vessels serving six coastal ports to get optimal results. An optimal solution to the problem is found with only two routes selected as the optimal shipping routes out of four routes that are considered. The results also showed that a vessel can be assigned to multiple shipping routes.
\end{abstract}

\section{Keywords}

Shipping Routes Design, Scheduling, Optimization, Strategic Planning, Coast Shipping

\section{Introduction}

Designing the shipping routes for container ships is very important not only for intercontinental shipping but also for coastal shipping. Shipping companies need to design the optimal shipping routes for their vessels to achieve the best operations. Designing shipping routes for homogeneous fleets is not as complicated as with heterogeneous fleets because of the different specifications of ships. As coastal shipping becomes increasing important especially by feeder vessels, it is vital that shipping companies design optimal routes for their fleets especially along shipping routes with navigable rivers. The dynamics of the shipping in- 
dustry makes it challenging for the actors in the industry to remain competitive. However, proper planning can improve their overall performance and reduce their overall operating cost. According to [1], there are three stages of decision making when designing shipping routes, especially when dealing with liner shipping. These stages are tactical, operational and strategic. The tactical stage deals with the scheduling of the vessels by developing the different routes and assigning the available fleets to these routes. The operational stage considers the cargoes to be shipped and the appropriate route to be used to ship the cargoes. Finally, the strategic stage deals with the optimal size and the number of ships to be deployed as it is essential for managing the operational cost of the ships.

This paper focuses on using an Operation Research (OR) model with the help of linear programming in ship routing and fleet scheduling to develop an optimal shipping route, especially for liner shipping feeder vessels. A case is used based on assumptions to give a general overview of how to model an optimal shipping route. The research aims to provide actors in the shipping industry who provide feeder services with a suitable method to develop optimal shipping route for its fleets. Modelling shipping routes of ocean transportation are different from modelling transportation routes from the other modes of transport because of the different characteristics of shipping routes even though some of the models can be adjusted to fit the other transport modes to obtain best results. Shipping routes are usually divided into different categories which include ocean, short-sea, coastal and inland waterways. The ultra-large vessels often serve the ocean routes while the smaller vessels such as the Panamax serve the short seas. To model optimal shipping routes, it is crucial to consider the size of the ship by considering its volume and weight carrying capacity. It is essential to know the Deadweight (DWT) of the vessel as well as the Gross Tons (GT) of the vessel. The DWT refers to the weight carrying capacity of a vessel which includes the weight of the vessel's lube oil, freshwater, fuel, provisions, machinery and cargo which is measured in metric tons.

Meanwhile, the GT refers to the volume of the ship space [2]. There are different types of feeder fleet sizes, and Table 1 demonstrates the dimensions of the

Table 1. Characteristics of ships according to ship type (source: Brouer et al. 2014).

\begin{tabular}{ccccccccc}
\hline Ship & $\begin{array}{c}\text { Capacity } \\
(\text { TEU })\end{array}$ & $\begin{array}{c}\text { Design } \\
\text { speed }(\mathrm{kn})\end{array}$ & $\begin{array}{c}\text { Max. } \\
\text { speed } \\
(\mathrm{kn})\end{array}$ & $\begin{array}{c}\text { Min. } \\
\text { speed } \\
(\mathrm{kn})\end{array}$ & $\begin{array}{c}\text { Draft } \\
(\mathrm{m})\end{array}$ & $\begin{array}{c}\text { Ideal } \\
\text { cost/day }(\$)\end{array}$ & $\begin{array}{c}\text { Fixed } \\
\text { daily } \\
\text { cost }(\$)\end{array}$ & $\begin{array}{c}\text { Bunking } \\
\text { cost }(\$) / \mathrm{nmi}\end{array}$ \\
\hline $\begin{array}{c}\text { Feeder } 450 \\
\text { Feeder-800 }\end{array}$ & 1600 & 12 & 14 & 10 & 8 & 1440 & 5000 & 39.17 \\
$\begin{array}{c}\text { Panamax } \\
1200\end{array}$ & 2400 & 18 & 19 & 12 & 12 & 2400 & 11,000 & 72.92 \\
$\begin{array}{c}\text { Panamax } \\
1750\end{array}$ & 3500 & 18 & 20 & 12 & 12 & 2700 & 15,000 & 76.39 \\
$\begin{array}{c}\text { Panamax } \\
2400\end{array}$ & 4800 & 16 & 22 & 12 & 11 & 3180 & 21,000 & 89.69 \\
\hline
\end{tabular}


various feeder vessels. Usually, the length of the ship's voyage will determine the type of vessel to be used. The longer the voyage or the shipping route, it will be better to use a larger vessel than a smaller vessel. It is to make use of the optimal ship size. Other factors that could be considered are the frequency of service provided by the feeder, cargo availability and cost with regards to the vessel usage.

From Table 1, capacity (TEU) refers to the vessel carrying capacity, which is the number of TEU's the vessel can carry. Design speed (kn) refers to the average speed the ship can deploy on a voyage while Max. and Min. speed (kn) refers to the maximum and the minimum speed the ship can deploy on a voyage. Draft (m) refers to the distance from the ship's load line to the hull (bottom) of the ship. The ideal cost/day refers to the cost the ship may incur per day once it's on the sea. Fixed daily cost refers to the cost the ship incurs daily whether in use or not and the bunking cost refers to the cost of fuel the ship uses on a voyage.

It is essential to consider the ports along the coastal line or the navigable river when developing the shipping routes for feeder vessels. It is vital to consider the handling capacity of the ports, accessibility to the port, and whether the port provides services such as bunkering, waste management, freshwater and ship supplies. Some coastal ports, especially in the developing countries, do not offer some of these services, so it is good to consider this in planning. There are different shipping route structures which include the hub \& feeder, circular, butterfly and pendulum as demonstrated in Figure 1. The type of structure to be

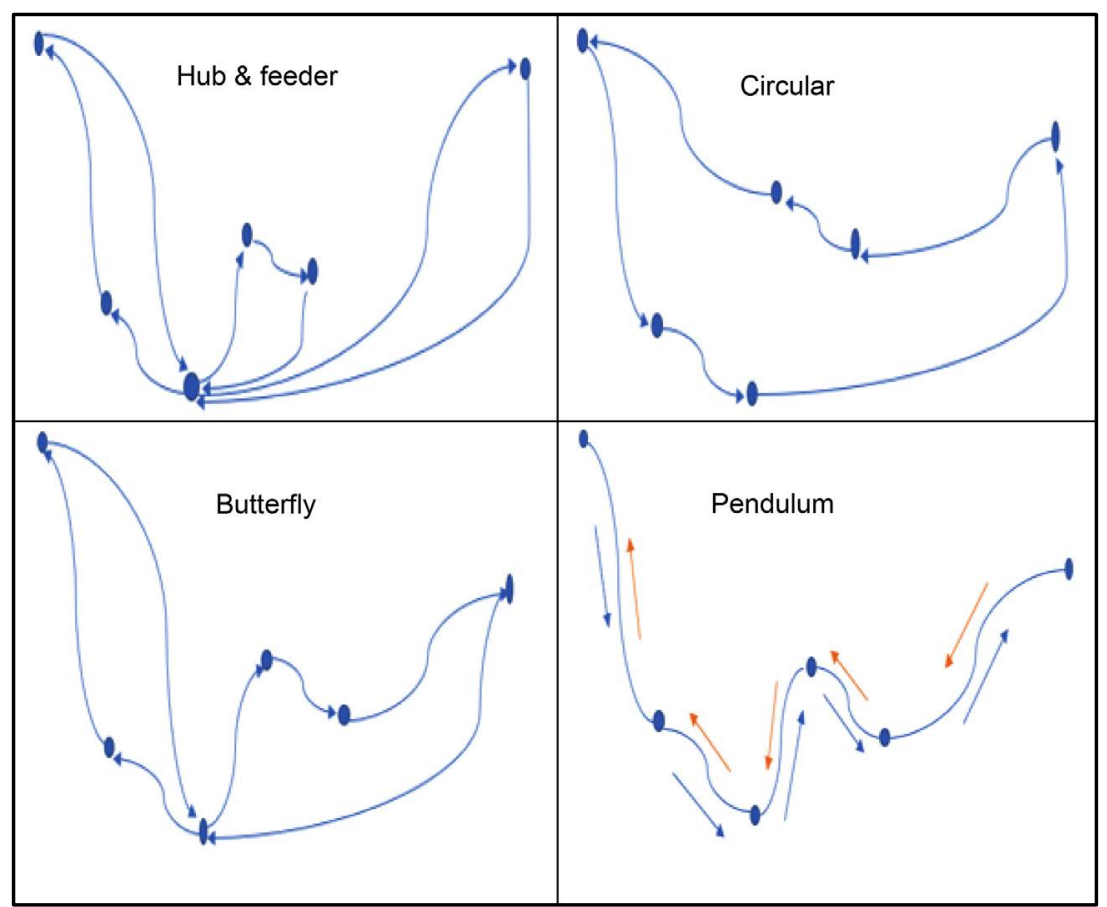

Figure 1. Different shipping route structures. Note: Hub \& feeder uses a hub port to receive and tranship goods to smaller ports. Circular route allows the first port of call be become the last port of call. Butterfly route is similar to the circular route but in this route one port can be visited twice. Pendulum route has each port visited twice except the last port. 
designed will depend on the number of fleets available. In the Hub \& feeder routing, smaller ships transport goods from relatively smaller ports to a big port which is considered as the hub port. The goods are then transferred to bigger ships which cannot have access to the smaller port, and these goods are then shipped to their final destination. Also, goods from these big ships meant for the smaller ports are transferred to the smaller ship for onwards transhipment to their final destinations. This type of routing network is economical because of the economics of scale of the bigger ships which enables them to carry a large number of goods over a longer distance. In this type of network, a hub port is selected based on the amount of TEUs the port can handle, accessibility of bigger vessels and also the distance relative to the other ports. So, the port location is critical. It should have a central location among the other ports. The circular route is designed in such a way that it will enable the first port to be the last port of call. This means that a ship can only visit a port just once in the whole voyage. This is a simple system, but the problem with it is the fact that goods meant for a port that has just been visited at the preceding port will have to go through a circle before they arrive the final destination which might be too long. The butterfly route design is almost the same with the circular network, but they differ in the fact that the later has sub-circles which gives it more advantage over the circular design. With the pendulum design, each port is visited twice except the port where the ship has to make a turnaround.

\section{Modelling Shipping Routes}

A significant amount of research has been done with the essence of modelling an optimal shipping route and shipping schedules. Some of the models capture the different planning stages for the different vessel categories and mixed problem types. When modelling strategic mixed fleet size, the main aim is to reduce the fixed and variable cost of the vessels. The strategic planning level also considers the sailing speed of the vessels with conjunction to a port time schedule which could be influenced by the weather conditions [3]. However, when considering the mixed tactical problem for routing and scheduling, most often than not, the aim is to reduce the operating cost of the vessels. The scheduling and tactical planning of shipping routes are essential for the cost efficiency and effectiveness in vessel operation [4]. One of the highest operational cost to consider is the cost of fuel. This is important because it has a direct and indirect relationship with the speed of the vessel [5]. When designing the shipping route of liner vessels, the vessel's sailing speed must be taken into consideration. [4] illustrate the fact that speed optimisation produces efficiency in a vessel's operation. However, when optimising a vessel's speed, it is essential to consider time-sensitive goods. Calculating a vessel's optimal fuel consumption from the speed of the vessel is an indispensable factor for achieving the efficiency of the vessel from the vessel's fuel usage per time as a function of speed. The faster the sailing speed of the vessel, the higher the amount of fuel consumed by the vessel [6] and hence, the 
higher the operating cost of the vessel [7]. The cost of fuel accounts for about $75 \%$ of a container vessel's operating cost [8], hence the need for an optimised shipping route. Shipping routes are developed not only to ensure an optimal cost of operation but also to ensure the appropriate capacity of the vessel facing several constraints [9]. Another vital cost to consider is the cost of the vessel because it will determine the fleet size to be deployed and what will determine the fleet size being used will be the time to be spent during a voyage and also time spent at the port [3] [5].

It is also important to know that transit time plays a vital role in the scheduling and designing container shipping routes. The estimation of transit time is one of the challenging aspects of shipping routes design [10]. It is always the case for shorter transit times to be designed not only when time-sensitive goods are shipped but also because of the high level of competition among shipping companies [11]. Transhipment time is also as vital as transit time. Transhipment refers to the transfer of a unit of container load from one vessel to another for onward shipment to the final destination [12]. [10] did their research on port delays due to uncertainties with its effect on transhipment and also transit time from one port to another. They sort to optimise the sailing speed for bunkering cost along a voyage of two ports of calls. Their work was applied to a liner networking with operations between Asia and Europe with a fleet of 14 vessels to serve 46 ports with a total of 100 routes utilised. They made use of different integrated, holistic algorithms which yielded optimal results and can be used as an excellent technique to solve liner routing problems.

[13] considered the different stages of planning and developed a linear programming (LP) problem as a multi-commodity flow problem were, they generated routes randomly and after studying the feasibilities of those routes then assign available fleets to those routes. [14] also used the multi-commodity flow problem to solve the ship scheduling and fleet routing problem as proposed by [13] and also used two linear programming algorithms which made used of pendulum routes and randomly generated routes to design the networks with a slight modification on the procedures. [15] used an integer programming approach to solve a joint cargo scheduling and the allocation of empty container problem. [1] used a mixed-integer programming model where they combined a column generation and a Benders decomposition-based algorithm to provide a solution to cargo-routing and shipping route scheduling problem. [16] also used a mixed-integer programming model by adopting a two-tier method. Other researchers have done extensive research on the different routing and scheduling methods that have been carried out over the years such as [17] who showed the different research work that had been done from 1983-1993. [18] Also researched the various trends of routing and scheduling of fleets from 1994-2004. Meanwhile, [19] did their research on the existing trend with proposals for further research options.

In their paper elaborated on the Liner Shipping Network Design Problem (LSNDP) and they did consider not only shipping route scheduling but also the 
fixed frequency of the ships to be deployed on those routes [20]. [21], did their research work at the tactical level where they evaluated the network in a hub \& spoke design which consisted of a direct route and a feeder route with a pair of ports serving as the nodes. They developed a two integer programming models to solve the problem with decision variables being the number of vessels to serves the different routes in the first model while the decision variables for the second model had to do with the number of voyages assigned to serve the different routes as well. They set their objective function to represent the cost of containers shipped. [22] based their research on a general liner shipping container routing and scheduling design problem along with several numbers of origin-destination points (O-D), with the deployment of a large number of vessels along multiple ports. Every container that was shipped along any particular O-D pair utilised more than one route. To ensure the competitiveness of the various ports, specific transit times along each route was known with bonuses and penalties awarded concerning differences in transit times. Their constraints were set to capture the arrival time of the vessel on any given route. They formulated a genetic search heuristic problem which was non-linear nor convex. [9] Sought to solve the liner shipping route design problem by formulating a nonlinear non-convex optimisation problem with the use of a dynamic programming method by utilising a space-time networking model. The primary objective was to optimise the vessels bunkering cost with port time windows serving as the constraints which yield him an optimal solution to the problem. [23] Considered to solve the problem by optimising the total cost of fuel consumption by the ships with weekly frequency and port time uncertainty as constraints by developing the problem as a nonlinear programming problem. They assumed that the ships always arrived at the ports at the exact time as given by the ports. They were able to obtain optimal results by using a stochastic approximation approach with a substantial amount of fuel-saving. [24] Evaluated the design of shipping routes by looking at uncertainties that might affect port activities such as delays in port handling operations or delays due to port congestion. Assuming that port delays might lead to a linear increase in port charges (penalties) and also that the delayed ship after leaving the port will have to increase its sailing speed in an effort to catch up with its schedule, they used a nonlinear mix-integer stochastic model to solve this problem with the aim of reducing the vessel's operating cost given all the uncertainties. They obtained near-optimal results within a reasonable time frame. Table 2 gives a summary of the recent research that has been done on designing liner shipping routes.

\section{Methodology}

This section describes the mathematical formulation used to design the shipping routing scheduling for heterogeneous feeder services along a coastal line using an integer and binary method on the variables as proposed by [2] with some modification in the calculation of fuel consumptions of the vessels. Assumptions are made to provide a holistic view of the problem. The problem is to determine 
Table 2. Summary of research done on shipping route scheduling.

\begin{tabular}{ccccc}
\hline Author & Network Type & $\begin{array}{c}\text { Cost } \\
\text { Optimization }\end{array}$ & $\begin{array}{c}\text { Speed } \\
\text { Optimization }\end{array}$ & $\begin{array}{c}\text { Port } \\
\text { Availability }\end{array}$ \\
\hline Mourao et al. (2001) & Single route & Yes & No & No \\
Bell et al., 2008 & Single & No & Yes & Yes \\
Wang et al. (2011) & Multiple routes & No & Yes & No \\
Qi et al. (2012) & Single route & Yes & No & No \\
Wang et al. (2012b) & Single route & Yes & Yes & No \\
Wang et al. (2012c) & Multiple routes & Yes & No & Yes \\
Psaraftis et al., 2013 & Multiple routes & Yes & Yes & Yes \\
Meng et al., 2014 & Multiple routes & No & Yes & Yes \\
Alharbi (2015) & Multiple routes & Yes & No & Yes \\
\hline
\end{tabular}

an optimal shipping route for heterogeneous fleets that could be deployed to service a pair of ports with fixed schedules. Multiple routes were evaluated with the optimal result giving a set of routes to be used by the available fleets. Each port pair has a minimum number of times they could be served within a known period. Because the fleet to be used is heterogeneous in nature, it therefore means that some vessels will not have access to some routes. The time required for loading and discharging at the ports are not showed but are considered in the voyage calculations. The factors that determine the usage of any route will be based on the capacities of the vessels.

\subsection{Situation Description}

$>$ There are 6 ports; port $1 \&$ port 4 are deep sea ports while ports 2, 3, $5 \& 6$ are river ports.

$>$ There are 5 ships in the set of fleets, 2 large ships and 3 small ships.

$>$ The entire planning horizon is 224 days.

Each route has its operating cost, and each ship has its fixed cost.

$>$ Each port pair has to be served not less than 3 times for the big ships and not less than 6 times for the small ships.

$V_{1} \& V_{3}$ are large ships while $V_{2}, V_{4} \& V_{5}$ are smaller ships.

The model description is shown in Figure 2, showing the different routes with the different port pairs serving each route. It represents a strategic fleet size and mix problem with predefined routes. Each route has some $N$ ports. As suggested by [25] one port has to be selected as the first port of call.

\subsection{A Mathematical Formulation of the Problem}

Let:

$V$-The set of ships indexed by $V$

$R v$-the set of routes sailed by ship $v$ indexed by $r$

$N$-Origin-destination port pairs indexed by $i$ with the ports numbered from 1 to $N$. It is required that each route has two end ports $i \& j$, where $1 \leq i \leq j \leq N$. 

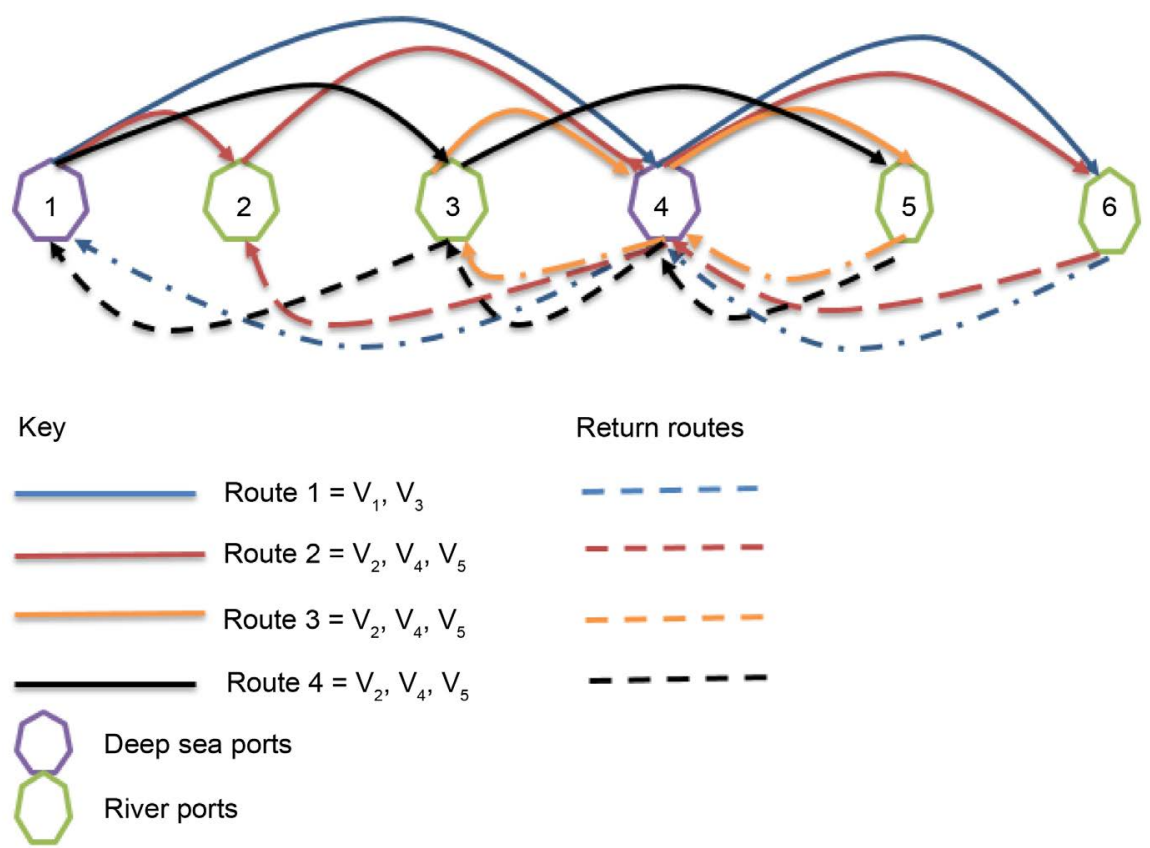

Figure 2. Routes serving different port pairs.

$D i$-least number of times a port pair is serviced during the planning horizon.

$C_{V v r}$-the cost of sailing one voyage with ship von route $r$

$C_{F_{V}}$-the fixed cost for ship $v$ during the planning horizon

$T_{V V T}$-time units taken by ship $v$ on route $r$

Cir - the cost of serving a port pair by ship von route $r$

Air-equals 1 if origin-destination port pair $i$ is serviced on route $r$, otherwise 0

$T$-Length of the planning horizon

$U_{V}$-an upper bound on the number of voyages ship $v$ can sail during the planning horizon. The unit cost used in this paper is the US Dollar (\$).

\subsection{Decision Variables}

$U_{V}, V \in V, r \in R V$, represents the number of voyages on route $r$ with ship $V$ during the planning horizon, and $S_{V}, V \in V$, is equal to 1 if ship $V$ is used. The model could be written as;

$$
\min \left[\sum_{v \in V} \sum_{r \in R v} C_{V v r}+\sum_{v \in V} C_{F v S v}\right]
$$

Subject to

$$
\begin{gathered}
\sum_{r \in R v} u_{v r}-U_{v S v} \leq 0, \quad \forall v \in V, \\
\sum_{v \in V} \sum_{r \in R v} A_{i r} u_{v r} \geq D_{i}, \quad \forall i \in N, \\
\sum_{r \in R v} T_{V v r} u_{v r} \leq T, \forall v \in V, \\
u_{v r} \geq 0 \text { integer }, \quad \forall v \in V, r \in R v, \\
S_{v} \in\{0,1\}, \forall v \in V .
\end{gathered}
$$


The primary objective function of the problem represented by Equation (1) is to minimise the cost of operating the six vessels and also the cost of sailing along each of the routes subject to a constraint set of 2 to 5 . Constraint (2) considers the fixed cost of operating a particular ship type. Constraint (3) specify the least number of times each port-paired should be served, and constraint (4) requires all the vessel to accomplish all tasks by sailing through all the routes within the given time horizon.

To determine the bunkering cost of each vessel on any route, it is essential to consider the maximum and the minimum speed of the vessel and also take the length of the voyage into consideration. This is important in the planning process because it will help in the decision-making. The vessel's fuel consumption is evaluated using the method proposed by [20].

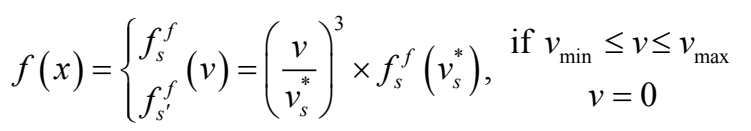

where, $f_{s}^{f}(v)$ represents the amount of fuel consumed per day in tons concerning the vessel's speed $v, v^{*}$ representing the ship-type $s$ designed speed and $f_{s}^{f}\left(v_{s}^{*}\right)$ representing the ship-type $s$ fuel consumption sailing at the intended speed while the ship's idle fuel consumption per day is represented by $f_{s i}^{f}$.

To determine an optimal solution for the deployment of all the vessels on the different routes, we assign each route the following port pairs. The final solution will determine which vessels should serve which port pairs on which route.

Port pairs on route 1 :

$$
\begin{aligned}
& N_{(1)}=\{1,4\}, N_{(2)}=\{1,6\}, N_{(3)}=\{4,6\}, \\
& N_{(4)}=\{6,4\}, N_{(5)}=\{6,1\}, N_{(6)}=\{4,1\}
\end{aligned}
$$

\section{Port pairs on route 2:}

$$
\begin{aligned}
& N_{(7)}=\{1,2\}, N_{(8)}=\{1,4\}, N_{(9)}=\{1,6\}, N_{(10)}=\{2,4\}, N_{(11)}=\{2,6\}, \\
& N_{(12)}=\{4,6\}, N_{(13)}=\{6,4\}, N_{(14)}=\{6,2\}, N_{(15)}=\{4,2\}
\end{aligned}
$$

Port pairs on route 3:

$$
N_{(15)}=\{3,4\}, N_{(17)}=\{3,5\}, N_{(18)}=\{4,5\}, N_{(19)}=\{5,4\}, N_{(20)}=\{5,3\}
$$

\section{Port pairs on route 4:}

$$
\begin{aligned}
& N_{(20)}=\{1,3\}, N_{(21)}=\{1,5\}, N_{(22)}=\{3,5\}, N_{(23)}=\{5,4\}, N_{(24)}=\{5,3\}, \\
& N_{(25)}=\{5,1\}, N_{(26)}=\{4,3\}, N_{(27)}=\{4,1\}, N_{(28)}=\{3,1\}
\end{aligned}
$$

where, $i \in N, \quad i=(1,2,3,4,5, \cdots, 31)$

The following parameters are assumed;

There are 6 ports; port $1 \&$ port 4 are deep sea ports while ports $2,3,5 \& 6$ are river ports.

There are 5 ships in the set of fleets, 2 large ships and 3 small ships.

The entire planning horizon is 224 days.

$>$ Each route has its operating cost, and each ship has its fixed cost. 
Each port pair has to be served not less than 3 times for the big ships and not less than 6 times for the small ships.

$V_{1} \& V_{3}$ are large ships while $V_{2}, V_{4} \& V_{5}$ are smaller ships.

$>$ Distance between port pairs are assumed as; $N\{1,2\}=2000 \mathrm{NM}, N\{2,3\}=$ $3000 \mathrm{NM}, N\{3,4\}=2500 \mathrm{NM}, N\{4,5\}=2000 \mathrm{NM}, N\{5,6\}=3500 \mathrm{NM}$.

Total port time on the various ports should not be more than 2 days.

We assume there are no delays at the port. Hence;

- Total port time on route $1=10$ days

- Total port time on route $2=12$ days

- Total port time on route $3=10$ days

- Total port time on route $4=12$ days

$>$ There is no ballast leg, hence optimum loaded speed (=15 kn).

$>$ Oil consumption is $40 \mathrm{t} / \mathrm{d}$ when sailing and port consumption $6 \mathrm{MT}$ for $V_{1} \&$ $V_{3}$ and $20 \mathrm{t} / \mathrm{d}$ when sailing and $3 \mathrm{MT}$ port consumption for $V_{2}, V_{4} \& V_{5}$.

Daily fixed cost for $V_{1}$ and $V_{3}=\$ 10,000$ each and $V_{2}, V_{4}$ and $V_{5}=\$ 5000$ each.

$>$ Port charges for ports $1,4 \& 6=\$ 6000$ each and for ports $2,3 \& 5=\$ 3000$ each.

$>$ The ports operate 24 hours per day, SHINC.

\subsection{Presentation of Data \& Result Analysis}

The voyage cost for a vessel sailing any route is vital for the designing of a shipping route because the cost along each route varies. The variation could be accounted for by the number of port calls along the route, the voyage distance, and the vessel speed are some of the important voyage components to consider. In this section, all the costs involved in the design of the shipping routes have been calculated and presented in Table 3 . All the cost includes the oil consumption by the vessels along each route and at the ports, port charges and the fixed cost of all the vessels.

Voyage cost per port pair for route 1

1) Port pair $N\{1,4\}$

\section{Sail time}

$7500 /(15 * 25)=20.83(d)$

Port time $=4(\mathrm{~d})$

\section{Oil consumption}

$20.83 * 40=833.2(\mathrm{t})$

$4 * 6=24(\mathrm{t})$

Total number of days $=(20.83+4)=24.83(\mathrm{~d})$

Fuel cost $=(833.2+24)=857.2 * \$ 125=\$ 107,150$

Port charge $=6000+6000=\$ 12,000$

Fixed cost $=\$ 10,000 * 2 * 24.83=\$ 496,600$

Total cost $=\$ 615,750$

2) Port pair $N\{4,6\}$

\section{Sail time}

$2000+3500 /(15 * 25)=15.28(d)$

Oil consumption

Port time $=4(\mathrm{~d})$ $15.28 * 40=611.2(\mathrm{t})$ $4^{\star} 6=24(\mathrm{t})$

Total number of days $=(15.28+4)=19.28(\mathrm{~d})$ 
Table 3. Cost associated with each route \& port pair (\$).

\begin{tabular}{|c|c|c|c|c|}
\hline Cir & R1 & R2 & R3 & R4 \\
\hline 12 & 245,500 & 167,800 & 167,800 & 167,800 \\
\hline 13 & 356,675 & 277,639 & 277,639 & 277,639 \\
\hline 14 & 615,750 & 389,593 & 389,593 & 389,593 \\
\hline 15 & 756,325 & 532,325 & 532,325 & 532,325 \\
\hline 16 & 997,750 & 705,425 & 705,425 & 705,425 \\
\hline 21 & 267,800 & 167,800 & 167,800 & 167,800 \\
\hline 23 & 476,000 & 234,857 & 234,857 & 234,857 \\
\hline 24 & 445,900 & 337,900 & 337,900 & 337,900 \\
\hline 25 & 887,000 & 654,546 & 654,546 & 654,546 \\
\hline 26 & 845,225 & 605,300 & 605,300 & 605,300 \\
\hline 31 & 397,645 & 277,639 & 277,639 & 277,639 \\
\hline 32 & 284,670 & 234,857 & 234,857 & 234,857 \\
\hline 34 & 291,950 & 191,950 & 191,950 & 191,950 \\
\hline 35 & 412,456 & 286,250 & 286,250 & 286,250 \\
\hline 36 & 745,250 & 598,345 & 598,345 & 598,345 \\
\hline 41 & 799,567 & 615,750 & 615,750 & 615,750 \\
\hline 42 & 410,324 & 337,900 & 337,900 & 337,900 \\
\hline 43 & 250,096 & 191,950 & 191,950 & 191,950 \\
\hline 45 & 247,564 & 167,800 & 167,800 & 167,800 \\
\hline 46 & 477,000 & 477,000 & 477,000 & 477,000 \\
\hline 51 & 678,456 & 532,325 & 532,325 & 532,325 \\
\hline 52 & 887,000 & 654,546 & 654,546 & 654,546 \\
\hline 53 & 412,456 & 289,250 & 289,250 & 289,250 \\
\hline 54 & 247,564 & 167,800 & 167,800 & 167,800 \\
\hline 56 & 310,000 & 234,500 & 234,500 & 234,500 \\
\hline 61 & 997,750 & 705,425 & 705,425 & 705,425 \\
\hline 62 & 845,225 & 605,300 & 605,300 & 605,300 \\
\hline 63 & 745,250 & 598,345 & 598,345 & 598,345 \\
\hline 64 & 477,000 & 477,000 & 477,000 & 477,000 \\
\hline 65 & 310,000 & 234,500 & 234,500 & 234,500 \\
\hline
\end{tabular}

Fuel cost $=(611.2+24)=635.2 * \$ 125=\$ 79,400$

Port charge $=6000+6000=\$ 12,000$

Fixed cost $=\$ 10,000 \star 2 * 19.28=\$ 385,600$

Total cost $=\$ 477,000$

\section{3) Port pair $N\{1,6\}$}

\section{Sail time}

\section{Oil consumption}

$2000+3000+2500+2000+3500 /(15 * 25)=36.11(d)$

Port time $=4(\mathrm{~d})$ $36.11 * 40=1444.4(\mathrm{t})$ $4{ }^{\star} 6=24(\mathrm{t})$ 
Total number of days $=(36.11+4)=40.11(\mathrm{~d})$

Fuel cost $=(1444.4+24)=1468.4 * \$ 125=\$ 183,550$

Port charge $=6000+6000=\$ 12,000$

Fixed cost $=\$ 10,000 * 2 * 40.11=\$ 802,200$

Total cost $=\$ 997,750$

Voyage cost per port pair for route 2

1) Port pair $N\{1,2\}$

\section{Sail time}

$2000 /\left(15^{\star} 25\right)=5.56(d)$

Port time $=4(\mathrm{~d})$

Total number of days $=(5.56+4)=9.56(\mathrm{~d})$

Fuel cost $=(111.1+12)=123.2 * \$ 125=\$ 15,400$

Port charge $=6000+3000=\$ 9000$

Fixed cost $=\$ 5000 * 3 * 9.56=\$ 143,400$

Total cost $=\$ 167,800$

\section{2) Port pair $N\{1,4\}$}

\section{Sail time}

$2000+3000+2500 /(15 * 25)=20.83(d)$

Port time $=4(\mathrm{~d})$

Oil consumption

$5.56 * 20=111.2(\mathrm{t})$

$4 * 3=12(\mathrm{t})$

\section{Oil consumption}

$20.83 * 20=416.6(\mathrm{t})$ $4 * 3=12(\mathrm{t})$

\section{Oil consumption}

$36.11 * 20=722.2(\mathrm{t})$

$4 * 3=12(\mathrm{t})$

Port time $=4(\mathrm{~d})$

Total number of days $=(36.11+4)=40.11(\mathrm{~d})$

Fuel cost $=(722.2+12)=734.2 * \$ 125=\$ 91,775$

Port charge $=6000+6000=\$ 9000$

Fixed cost $=\$ 5000 * 3 * 40.11=\$ 601,650$

Total cost $=\$ 705,425$

4) Port pair $N\{2,4\}$

\section{Sail time}

$3000+2500 /(15 * 25)=15.28(d)$

Port time $=4(\mathrm{~d})$

Total number of days $=(15.28+4)=19.28(\mathrm{~d})$

Fuel cost $=(305.6+12)=317.6 * \$ 125=\$ 39,700$

Port charge $=6000+3000=\$ 9000$

Fixed cost $=\$ 5000 * 3 * 19.28=\$ 289,200$

Total cost $=\$ 337,900$

5) Port pair $N\{2,6\}$

\section{Oil consumption}

$15.28 * 20=305.6(\mathrm{t})$ $4 * 3=12(\mathrm{t})$ 


\section{Sail time}

$11,000 /(15 * 25)=30.56(d)$

Port time $=4(\mathrm{~d})$

Total number of days $=(30.56+4)=34.56(\mathrm{~d})$

Fuel cost $=(611.2+12)=623.2 * \$ 125=\$ 77,900$

Port charge $=6000+3000=\$ 9000$

Fixed cost $=\$ 5000 * 3 * 34.56=\$ 518,400$

Total cost $=\$ 605,300$

Voyage cost per port pairs for route 3

1) Port pair $N\{3,4\}$

\section{Sail time}

$2500 /(15 * 25)=6.94(d)$

Port time $=4(\mathrm{~d})$

Total number of days $=(6.94+4)=10.94(\mathrm{~d})$

Fuel cost $=(138.8+12)=150.8 * \$ 125=\$ 18,850$

Port charge $=6000+3000=\$ 9000$

Fixed cost $=\$ 5000 * 3 * 10.94=\$ 164,100$

Total cost $=\$ 191,950$

2) Port pair $N\{3,5\}$

\section{Sail time}

$2000+2500 /(15 * 25)=12.5(d)$

Port time $=4(\mathrm{~d})$

Total number of days $=(12.5+4)=16.5(\mathrm{~d})$

Fuel cost $=(12.5+12)=262 * \$ 125=\$ 32,750$

Port charge $=6000+3000=\$ 9000$

Fixed cost $=\$ 5000 * 3 * 9.56=\$ 247,500$

Total cost $=\$ 286,250$

3) Port pair $N\{4,5\}$

\section{Sail time}

$2000 /(15 * 25)=5.56(d)$

Port time $=4(\mathrm{~d})$

Total number of days $=(5.56+4)=9.56(d)$

Fuel cost $=(111.1+12)=123.2 * \$ 125=\$ 15,400$

Port charge $=6000+3000=\$ 9000$

Fixed cost $=\$ 5000 * 3 * 9.56=\$ 143,400$

Total cost $=\$ 167,800$

Voyage cost per port pair for route 4

1) Port pair $N\{1,3\}$

\section{Sail time}

$2000+3000 /(15 * 25)=13.89(d)$

Port time $=4(\mathrm{~d})$

Total number of days $=(5.56+4)=17.89(\mathrm{~d})$

Fuel cost $=(277.8+12)=277.8 * \$ 125=\$ 289.8$

Port charge $=6000+3000=\$ 9000$
Oil consumption

$30.56 * 20=611.2(\mathrm{t})$

$4 * 3=12(\mathrm{t})$

Oil consumption

$6.94 * 20=138.8(\mathrm{t})$

$4 * 3=12(\mathrm{t})$

Oil consumption

$12.5 * 20=250(\mathrm{t})$

$4 * 3=12(\mathrm{t})$

\section{Oil consumption}

$5.56 * 20=111.2(\mathrm{t})$

$4 * 3=12(\mathrm{t})$

\section{Oil consumption}

$13.89 * 20=277.8(\mathrm{t})$

$4 * 3=12(\mathrm{t})$ 
Fixed cost $=\$ 5000 * 3 * 17.89=\$ 268,350$

Total cost $=\$ 277,639$

2) Port pair $N\{1,5\}$

\section{Sail time}

Oil consumption

$9500 /(15 * 25)=26.39(\mathrm{~d})$

Port time $=4(\mathrm{~d})$

Total number of days $=(26.39+4)=30.39(\mathrm{~d})$

Fuel cost $=(527.8+12)=539.8 * \$ 125=\$ 67,475$

Port charge $=6000+3000=\$ 9000$

Fixed cost $=\$ 5000 * 3 * 30.39=\$ 455,850$

Total cost $=\$ 532,325$

3) Port pair $N\{3,5\}$

\section{Sail time}

$2000+2500 /(15 * 25)=12.5(d)$

Port time $=4(\mathrm{~d})$

Total number of days $=(12.5+4)=16.5(\mathrm{~d})$

Fuel cost $=(250+12)=262 * \$ 125=\$ 32,750$

Port charge $=3000+3000=\$ 6000$

Fixed cost $=\$ 5000 * 3 * 16.5=\$ 247,500$

On route 1 , the cost associated with the port pairs are as follows;

$$
\begin{aligned}
& N_{1}\{1,4\}=\$ 615750, N_{2}\{1,6\}=\$ 997750, N_{3}\{4,6\}=\$ 477000, \\
& N_{4}\{6,4\}=\$ 477000, N_{5}\{6,1\}=\$ 997750, N_{6}\{4,1\}=\$ 799567 .
\end{aligned}
$$

On route 2 , the cost associated with the port pairs are as follows;

$$
\begin{aligned}
& N_{7}\{1,2\}=\$ 167800, N_{8}\{1,4\}=\$ 615750, N_{9}\{1,6\}=\$ 705425, \\
& N_{10}\{2,4\}=\$ 337900, N_{11}\{2,6\}=\$ 605300, N_{12}\{4,6\}=\$ 477000, \\
& N_{13}\{6,4\}=\$ 477000, N_{14}\{6,2\}=\$ 605300, N_{15}\{4,2\}=\$ 337900 .
\end{aligned}
$$

On route 3 , the cost associated with the port pairs are as follows;

$$
\begin{aligned}
& N_{15}\{3,4\}=\$ 191950, N_{17}\{3,5\}=\$ 286250, N_{18}\{4,5\}=\$ 167800, \\
& N_{19}\{5,4\}=\$ 167800, N_{20}\{5,3\}=\$ 286250 .
\end{aligned}
$$

On route 4, the cost associated with the port pairs are as follows;

$$
\begin{aligned}
& N_{20}\{1,3\}=\$ 277639, N_{21}\{1,5\}=\$ 532325, N_{22}\{3,5\}=\$ 286250, \\
& N_{23}\{5,4\}=\$ 167800, N_{24}\{5,3\}=\$ 286250, N_{25}\{5,1\}=\$ 532325, \\
& N_{26}\{4,3\}=\$ 191950, N_{27}\{4,1\}=\$ 615750, N_{28}\{3,1\}=\$ 277639 .
\end{aligned}
$$

The total cost of operating all the five ships on the four shipping routes within the 224 days of planning horizon amounts to $\$ 52,636,134$. Table 4 shows the assumed shipping routes with the different port pairs before the simulation of the problem.

The results for the assignment of the fleets showing the optimised result for the shipping routes are presented in Table 5.

The results from Table 5 represent the optimal shipping routes and the 
Table 4. Port pairs on each route served by a vessel.

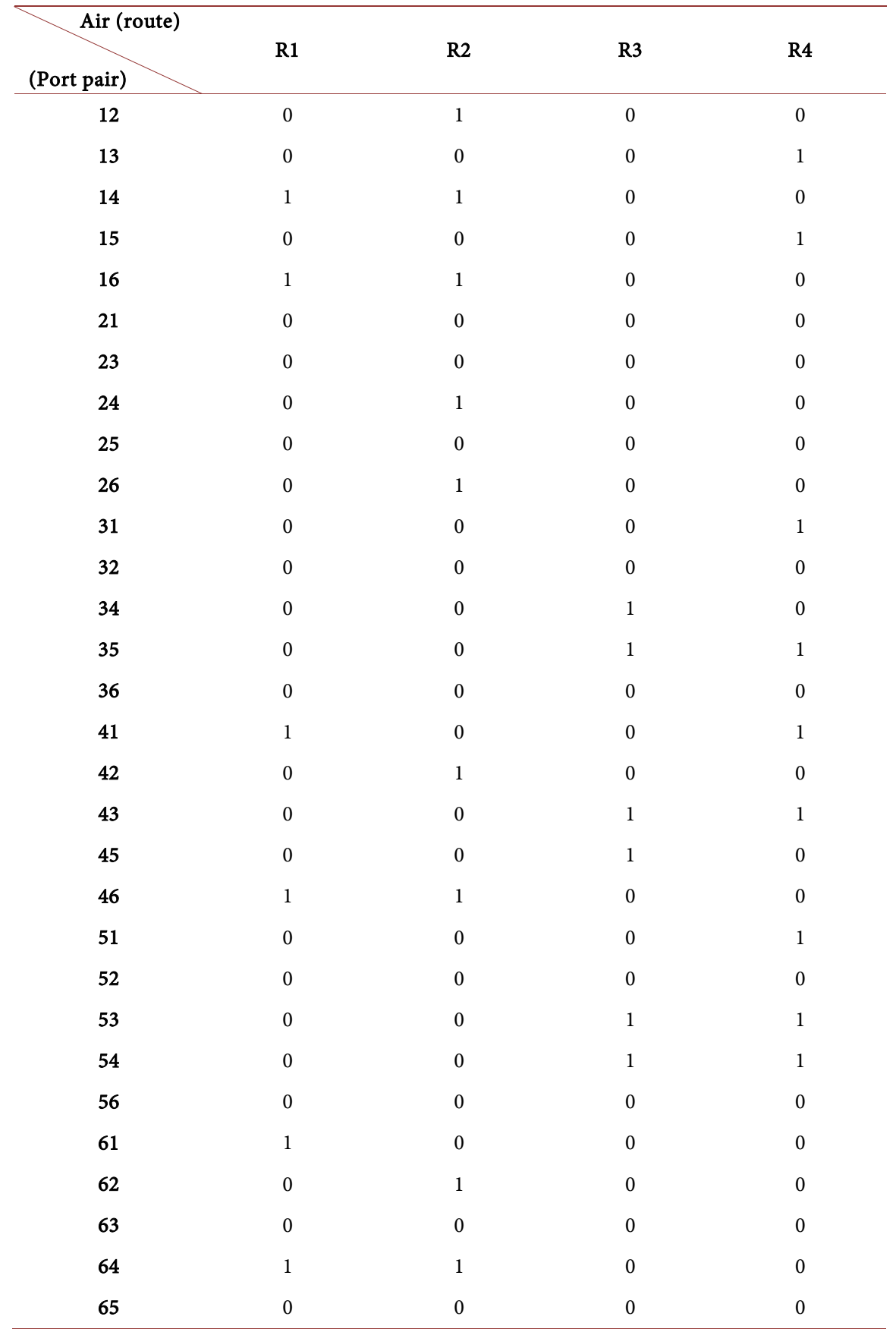

port-pairs associated with each route after the simulation. Out of the four routes proposed to be served by the five fleets, only route 1 and route 2 turned to be the most optimised routes while route 3 and 4 were not selected. On route 1 , the port pairs are $\{2,1\},\{3,2\},\{4,6\}$, and $\{6,4\}$. This means that the vessels deployed on route 1 will have to serve port 1 , port 2 , port 3 , port 4 and port 6 . From the port pairs served on route 1, only one large vessel $V_{1}$ or $V_{3}$ can serve port pair $\{4,6\}$ and $\{6,4\}$ and at the same time only one smaller vessel $V_{2}, V_{3}$ or $V_{4}$ can be assigned on route 1 to serve port pairs $\{1,2\},\{2,3\}$ and vice versa. It means that 
Table 5. Optimal port pair routes.

\begin{tabular}{|c|c|c|c|c|}
\hline Air & $\mathbf{R} 1$ & R2 & R3 & R4 \\
\hline 12 & 0 & 1 & 0 & 0 \\
\hline 13 & 0 & 1 & 0 & 0 \\
\hline 14 & 0 & 1 & 0 & 0 \\
\hline 15 & 0 & 1 & 0 & 0 \\
\hline 16 & 0 & 1 & 0 & 0 \\
\hline 21 & 1 & 0 & 0 & 0 \\
\hline 23 & 0 & 1 & 0 & 0 \\
\hline 24 & 0 & 1 & 0 & 0 \\
\hline 25 & 0 & 1 & 0 & 0 \\
\hline 26 & 0 & 1 & 0 & 0 \\
\hline 31 & 0 & 1 & 0 & 0 \\
\hline 32 & 1 & 0 & 0 & 0 \\
\hline 34 & 0 & 1 & 0 & 0 \\
\hline 35 & 0 & 1 & 0 & 0 \\
\hline 36 & 0 & 1 & 0 & 0 \\
\hline 41 & 0 & 1 & 0 & 0 \\
\hline 42 & 0 & 1 & 0 & 0 \\
\hline 43 & 0 & 1 & 0 & 0 \\
\hline 45 & 0 & 1 & 0 & 0 \\
\hline 46 & 1 & 0 & 0 & 0 \\
\hline 51 & 0 & 1 & 0 & 0 \\
\hline 52 & 0 & 1 & 0 & 0 \\
\hline 53 & 0 & 1 & 0 & 0 \\
\hline 54 & 0 & 1 & 0 & 0 \\
\hline 56 & 0 & 1 & 0 & 0 \\
\hline 61 & 0 & 1 & 0 & 0 \\
\hline 62 & 0 & 1 & 0 & 0 \\
\hline 63 & 0 & 1 & 0 & 0 \\
\hline 64 & 1 & 0 & 0 & 0 \\
\hline 65 & 0 & 1 & 0 & 0 \\
\hline
\end{tabular}

on route 1 , only port 5 will not be served.

Route 2 appears to be the most used route and the port pairs that are served are $\{1,2\},\{1,3\},\{1,4\},\{1,5\},\{1,6\},\{2,3\},\{2,4\},\{2,5\},\{2,6\},\{3,1\},\{3,4\},\{3,5\},\{3,6\}$, $\{4,1\},\{4,2\},\{4,3\},\{4,5\},\{5,1\},\{5,2\},\{5,3\},\{5,4\},\{5,6\},\{6,1\},\{6,2\},\{6,3\},\{6,5\}$. Vessels deployed on route 2 will have to serve port 1, port 2, port 3, port 4, port 5 and port 6. Given the fact that there are only two large vessels $V_{1}$ and $V_{2}$ and considering that one of these ships have been employed on route 1 , the other large ship can be deployed on route 2 to serve port pairs $\{1,2\},\{2,3\}$ and vice versa. Even though the large ship assigned on route 1 to serve port pair $\{4,6\}$ can 
still serve on round 2 to serve in the same capacity. For example, if $V_{3}$ was assigned on route 1 to serve port pair $\{4,6\}$, it can still serve that port pair in route 2 while $V_{1}$ is assigned on route 2 to serve port pair $\{1,4\}$ and $\{4,1\}$. In the same way, while one vessel, say $V_{2}$ is being assigned to service route 1 , the remaining two vessels $V_{4}$ and $V_{5}$ will be assigned to service route 2 . Vessels $V_{4}$ and $V_{5}$ can be deployed to serve port pairs $\{3,4\},\{4,5\},\{5,6\}$ and vice versa. This is very interesting because this implies that a single vessel can be assigned to multiple routes provided the vessel's ports of call are along those routes, and the vessel does not have to be deployed from the main port of origin. The optimal cost for serving route 1 by $V_{1}, V_{2}$ and route 2 by the $V_{3}, V_{4}, V_{5}$ amounts to $\$ 48,308,172$. Comparing this cost to the cost of serving route $1,2,3, \& 4$, there is a saved cost of $\$ 4,327,962$.

\section{Conclusion}

Designing shipping routes for heterogeneous fleets to be deployed in a coastal shipping route is very import for strategic planning by coastal shipping liner operators. There are different methods of evaluation that could be used to obtained optimal results, and one of those methods is to make use of operation research models based on linear programming. To successfully implement such a model, it is important to get all the necessary information regarding the characteristics of the vessels, the voyage cost of all the designed routes which includes the cost of fuel, the ship's fixed cost, port charges and canal dues if it applies. One interesting fact from the result was the ability of a vessel to serve more than one route. This means that a shipping line with limited vessels can strategical allocate its vessel to service multiple routes at the same time optimising the cost of operation provided the vessel's ports of call are along those different shipping routes. Another interesting observation is the fact that it is more economical to have a heterogeneous fleet of bigger and smaller vessels when operating a liner service on coastal shipping routes rather than the use of only smaller vessels. The limitation of this paper concerns the number of ports and vessels taken into consideration, and it creates room for future research to be done why increasing the number of port and vessels used.

\section{Conflicts of Interest}

The author declares no conflicts of interest regarding the publication of this paper.

\section{References}

[1] Agarwal, R. and Ergun O. (2008) Ship Scheduling and Network Design for Cargo Routine in Liner Shipping. Transportation Science, 42, 175-196.

https://doi.org/10.1287/trsc.1070.0205

[2] Marielle, C., Kjetil, F. and Bjørn N. (2007) Chapter 4 Maritime Transportation. Handbooks in Operations Research and Management Science, 4, 189-284. https://doi.org/10.1016/S0927-0507(06)14004-9 
[3] Meng, Q., Wang, S., Andersson, H. and Thun, K. (2014) Container Routing and Scheduling in Liner Shipping: Overview and Future Research Directions. Transportation Science, 48, 265-280. https://doi.org/10.1287/trsc.2013.0461

[4] Wang, T., Meng, Q. and Wang, S. (2012) Robust Optimisation Model for Liner Ship Fleet Planning with Container Transhipment and Uncertain Demand. Transportation Research Record, 2273, 18-28. https://doi.org/10.3141/2273-03

[5] Psaraftis, H.N. and Kontovas, C.A. (2013) Speed Model for Energy-Efficient Maritime Transportation: A Taxonomy Survey. Transportation Research Part C, 26, 331-351. https://doi.org/10.1016/j.trc.2012.09.012

[6] Wang, S., Meng, Q. and Liu, Z. (2013) Bunker Consumption Optimisation Methods in Shipping. A Critical Review and Extension. Transportation Research Part E, 53, 49-62. https://doi.org/10.1016/j.tre.2013.02.003

[7] Notteboom, T. and Vernimmen, B. (2009) The Effect of High Fuel Cost on Liner Service Configuration in Container Shipping. Journal of Transport Geography, 17, 325-337. https://doi.org/10.1016/j.jtrangeo.2008.05.003

[8] Ronen, D. (2011) The Effect of Oil Price on Containership Speed and Fleet Size. Journal of Operational Research Society, 62, 211-216.

https://doi.org/10.1057/jors.2009.169

[9] Alharbi, A.F.M. (2015) Scheduling Design for Liner Shipping Network with Port Time Windows. University of Wollongong Research Online.

[10] Wang, S. and Meng, Q. (2012) Liner Ship Route Schedule Design with Sea Contingency Time and Port Time Uncertainty. Transportation Research Part B, 46, 615633. https://doi.org/10.1016/j.trb.2012.01.003

[11] Bell, M.G.H. and Bichou, K. (2008) An Analysis of Speed and Scheduling Stability for Container Liner Services. Maritime Economics and Logistics, 10, 175-184.

https://doi.org/10.1057/palgrave.mel.9100197

[12] Lachner, S. and Boskamp, V. (2011) Routing and Scheduling in Liner Shipping with Multi-Start Local Search Heuristics. Erasmus School of Economics, Erasmus University Rotterdam, the Netherlands.

[13] Mulder, J. and Dekker, R. (2013) Methods for Strategic Liner Shipping Network Design. European Journal of Operation Research, 235, 367-377.

https://doi.org/10.1016/j.ejor.2013.09.041

[14] Lisanne, V.R. (2015) Service Network Design for Liner Shipping in Indonesia. Erasmus University in Economics and Operations Research.

[15] Song, J.P. and Dong, J.X. (2012) Cargo Routing and Empty Container Repositioning I Multiple Shipping Service Routes. Transportation Research Part B, 46, 1556-1575. https://doi.org/10.1016/j.trb.2012.08.003

[16] Alvarez, J.F. (2009) Joint Routing and Deployment of a Fleet Container Vessels. Maritime Economics \& Logistics, 11, 186-208. https://doi.org/10.1057/mel.2009.5

[17] Ronen, D. (1993) Cargo Ships Routing and Scheduling: Survey of Models and Problems. European Journal of Operation Research, 12, 119-126. https://doi.org/10.1016/0377-2217(83)90215-1

[18] Christiansen, M., Fagerholt, K. and Ronen, D. (2004) Ship Routing and Scheduling: Statutes and Perspectives. Transportation Science, 38, 1-18. https://doi.org/10.1287/trsc.1030.0036

[19] Wang, S. and Meng, Q. (2011) International Maritime-Port Technology and Development Conference. Chapter Liner Ship Routing and Scheduling: State of the Art, 69-74. 
[20] Brouer, B., Alvarez, J., Plum, C., Pisinger, D. and Sigurd, M. (2014) A Base Integer Programming Model and Benchmark Suite for Liner Shipping Network Design. Transportation Science, 48, 281-312. https://doi.org/10.1287/trsc.2013.0471

[21] Mourao, M., Pato, M.V. and Paixao, A.C. (2001) Ship Assignment with Hub and Spoke Constraints. Maritime Policy and Management, 29, 135-150. https://doi.org/10.1080/03088830110078364

[22] Wang, S. and Meng, Q. (2011) Schedule Design and Container Routing in Liner Shipping. Transportation Research Records, 2222, 25-33. https://doi.org/10.3141/2222-04

[23] Brouer, B., Desaulniers, G. and Pisinger, D. (2014) A Metaheuristics for the Liner Shipping Network Design Problem. Transportation Research Part E, 72, 42-59. https://doi.org/10.1016/j.tre.2014.09.012

[24] Qi, X. and Song, D.P. (2012) Minimizing Fuel Emissions by Optimising Vessel Schedules in Liner Shipping with Uncertain Port Times. Transport Research Part E, 48, 863-880. https://doi.org/10.1016/j.tre.2012.02.001

[25] Wang, S. and Meng, Q. (2012) Robust Schedule Design for Liner Shipping Services. Transportation Research Part E, 48, 1093-1106.

https://doi.org/10.1016/j.tre.2012.04.007 